\title{
ITINERARIOS URBANOS EN LA CELESTINA DE FERNANDO DE ROJAS
}

\author{
Patrizia Botta \\ Università di Roma
}

La Celestina de Fernando de Rojas (=LC), publicada por primera vez en 1499, está ambientada, como todos saben, en una ciudad española de fines del siglo XV que su autor ha dejado sin nombrar.

Ya varios críticos ${ }^{1}$ han apuntado que es una obra fundamentalmente urbana, no sólo por el escenario elegido y por los personajes que en ella actúan - todos ellos tipos ciudadanos - sino también por reflejar la nueva economía dineraria que, frente a la rural, también hallaba su cabida en las ciudades, donde circulaban la moneda y varias clases de bienes materiales. Urbanos son también, en la obra, el deseo de lucro, la búsqueda del placer y gasto superfluo, la ostentación de la casa y la constante preocupación por las apariencias. En palabras de J.A. Maravall:

el mundo social celestinesco es un producto de la civilización urbana, en correspondencia con el auge que ésta toma en el Renacimiento...LC es un típico, inconfundible producto de la cultura ciudadana. (60-61)

En efecto, es el mismo texto el que deja bien claro que el lugar donde se desenvuelve la acción dramática es una "ciudad" (y no una 'aldea' o una 'villa'), siendo además frecuentes las menciones de la

\footnotetext{
${ }^{1}$ Entre ellos Maravall y Samonà. Ver la Bibliografia.
} 
palabra en la obra: se cuentan 23, de las que la más famosa es la que profiere en el Auto III Celestina:

En esta ciudad nascida, en ella criada, manteniendo honrra, como todo el mundo sabe, ¿conoçida, pues, no soy? ${ }^{2}$

Y esta ciudad no sólo es subrayada mediante su nombre, sino también es evocada constantemente a través de sus numerosos componentes materiales, como veremos más adelante.

Ahora bien: la ciudad en que está ambientada LC no es mero telón de fondo: muchas de las escenas se dan directamente en la calle, o delante de una iglesia o detrás de una puerta. Sus espacios reales sirven a la acción del drama, son necesarios para que los acontecimientos se preparen o incluso ocurran. Como todos recordarán, la acción de LC está intimamente ligada a los movimientos que realizan ciertos personajes para trasladarse de un lugar a otro, o mejor, de una casa a otra, comenzando por su personaje central, Celestina, que el mismo texto define como "trotaconventos" (II.77), con evidente alusión textual al Libro de Buen Amor.

En la obra son cinco las casas que se nombran: tres son las casas principales (de Calisto, de Melibea, de Celestina), y dos las casas secundarias (de Areúsa y de Centurio). Además hay acciones que se desenvuelven en la iglesia y otras que se nos cuentan como ocurridas en la plaza. Las calles que unen ese conjunto de moradas y de sitios forman una densa red urbana que es recorrida por varios personajes de la obra, en una larga serie de viajes de ida y vuelta, o en un amplio sistema de movimientos que configura lo que Samonà ha definido como la "estructura itinerante" de la obra (232-36). Y si algunos de esos viajes son narrados, otros en cambio, la mayoría, ocurren directamente en la escena, es decir, formando parte de la acción dramática y dando lugar a varios parlamentos callejeros, o bien a soliloquios por el camino.

${ }^{2}$ Las citas celestinescas proceden del texto publicado en Zaragoza 1507, del que estamos llevando a cabo una edición. Para comodidad del lector, de aquí en adelante indicaremos para cada una el personaje, el auto y las páginas correspondientes en la edición Alianza llevada a cabo por Dorothy Severin en 1969. En el caso presente se trata de Celestina, III.81. 
En efecto, son 27 las escenas que se pasan enteramente en la calle, ${ }^{3}$ repartidas, a lo largo de la obra, entre todos los actos salvo el VI (todo él en casa de Calisto), el XV (en casa de Areúsa), y el XVI, el XX y el XXI (los tres en casa de Pleberio). Los trayectos recorridos durante la acción son 6:

1. El que une las casas de Calisto y Celestina y es el más frecuentado, con varias escenas que se dan en él: I.58, III.79, V.103, VII.119, IX:142;

2. El que va de la casa de Celestina a la de Melibea: IV.86, V.102;

3. El que une las casas de Calisto y Melibea: XII.169, XIV.192, XIX.218;

4. El que va desde la casa de Calisto a la de Areúsa: VIII.135;

5. El que une las casas de Elicia/Celestina y Areúsa: XVII.209;

6. El que une la casa de Melibea a la iglesia de la Magdalena: XI.163.

Los personajes que resultan ser más callejeros durante la acción son, ante todo, Sempronio, con 11 presencias en la calle, seguido por la alcahueta y Pármeno, con 10 presencias cada uno, luego Calisto, Sosia y Tristán (con 7) y en fin Elicia, Lucrecia y Alisa (con 1).

Quienes profieren monólogos por el camino son Celestina, que recita dos (en IV.86 y en V.102), Pármeno (uno en VIII.135), y Elicia (uno en XVII.208). Quienes dialogan más a menudo son Celestina y los dos criados, luego Sempronio y Pármeno, Calisto y sus siervos, y en fin los cuatro juntos, es decir la alcahueta, Calisto y sus criados.

Ahora bien: los recorridos que estos personajes realizan en cada una de esas situaciones callejeras siguen los itinerarios urbanos de una ciudad española medieval. La ciudad, aunque no esté especificada, se nos presenta nítida a los ojos, pormenorizada en sus detalles concretos, en su vida diaria, y hasta en sus voces y pregones. Ya María Rosa Lida en los anos '60 había trazado un 'inventario' de los elementos ciudadanos presentes en la obra de Rojas, en un capítulo no aprovechado para su monografía La originalidad artística de $L C{ }^{4}$ que se publicó póstumo y que aquí retomaremos completándolo y ampliándolo con varios datos nuevos.

De la ciudad se nos nombran ante todo sus habitantes, que pertenecen a distintas clases sociales (ricos, caballeros, clérigos, criados,

${ }^{3}$ Hemos tenido en cuenta la división en escenas establecida por Czarnocka, de la que hemos entresacado las 27 escenas callejeras mencionadas.

- Ver en la Bibliografía, Lida, «El ambiente concreto en LC». 
prostitutas) y que además ejercen gran cantidad de oficios: entre la gente de justicia, por ejemplo, se nombran el juez (Calisto, XIV.194), ${ }^{5}$ el alcalde (Ibid.), el veedor y regidor (Celestina, III.85), el procurador (Celestina, III.80), los falsos testigos (Celestina, VII.125), el alguacil (Sempronio, XII.176), el pregonero (Sosia, XIII.187) y el verdugo "bozeador" (Calisto, XIV.195).

Sabemos además que hay médicos (Celestina, X.155), cirujanos (Celestina, III.82) a la vez que parteras (Celestina, VII.123) y físicas de niños (Pármeno, I.61). Una larga serie de oficios típicamente ciudadanos es la que Pármeno, en su famosa descripción, enumera deteniéndose en los más ruidosos, o sea, herreros, carpinteros, armeros, herradores, caldereros, arcadores, peinadores y tejedores (Pármeno, I.59-60). Además, hay curtidores que trabajan en las malolientes tenerías (Pármeno, 1.60 y 67; Lucrecia, IV.88; Melibea, IV.92), como también se alude al orfebre (Celestina, I.73), al albañil, al buhonero (Sempronio, IX.145), al mesonero de la plaza y al hortelano (Sempronio, XII.176), al rufián espadachín (Argumento, XV.197) y al ladrón (Alisa, X.162).

Entre los oficios típicamente femeninos, tenemos ante todo los que se indican para Celestina, que en la descripción de Pármeno son seis, y "más de treinta" en frase de Lucrecia, a saber: "labrandera, perfumera, maestra de hazer afeites e de fazer virgos, alcahueta e un poquito hechicera" (Pármeno, 1.60). Además "perfuma tocas, haze solimán...conoce mucho en yervas, cura niños y aun algunos la llaman la vieja lapidaria" (Lucrecia, IV.88). También son mencionadas las pasteleras (como la madre de Areúsa, XV.202), las hilanderas y corredoras de hilados (Celestina, III.83), las prostitutas y las criadas (como Lucrecia).

En cuanto a la ciudad en que vive la gran galería de tipos mencionados también se nos presenta en sus detalles materiales, que a lo largo de la obra se nos pincelan reiteradas veces, como ya se ha dicho. Si miramos a las construcciones urbanas, en el campo de las viviendas son muchas las palabras mencionadas, entre ellas casa (desde luego muy frecuente), y después morada, posada, edificio, palacio, puerta, portón, torre, azotea, paredes, ventana, techo y muchas más. También se nombran algunos edificios públicos, entre ellos varias veces la iglesia, para la que incluso

${ }^{5}$ A partir de este momento, daremos tan sólo un ejemplo para cada una de las palabras mencionadas, salvo en un par de casos. En el presente, se trata de Calisto, XIV.194. 
se nos dan dos nombres propios (la de la Magdalena, ${ }^{6}$ en la que Celestina concierta sus tramas y la de San Miguel, donde sirvió Sempronio [XII.176]); iglesias, además, de donde claman varias veces las campanas (Melibea, XX.229), o adonde los personajes van a misa (Calisto, VIII.140). También se habla de templos y de monasterios (Sosia, XIV.192; Pármeno, I.61), y entre las demás construcciones se citan el hospital (Celestina, VII.120), el sepulcro (Pleberio, XX.226), el cementerio (Celestina, VII.122), las tenerías (Pármeno, I. 60 y 67; Lucrecia, IV.88; Melibea, IV.92) y el burdel (Pármeno, I.65) (o putería [Areúsa, XV.198]).

En cuanto a la vida y a la organización de la ciudad, se nos habla de la feria (Melibea, IV.91; Pleberio, XX.233), de las tiendas (Elicia, IX.145), de la plaza del mercado (Celestina, VII.124) con sus voces y sus pregones (Sosia, XIII.186), donde también se ejecutan a los "públicos malhechores" (Ibid.) o se empicotan a las hechiceras (Lucrecia, IV.88; Celestina, VII.124), o incluso se corren toros (Celestina, VI.108). También se nombra varias veces al mesón (Sempronio, VIII.136), a las tabernas y a los bodegones (Celestina, III.82). Y no falta el reloj (Celestina, XI.165), que con sus toques marca el tiempo y organiza la vida cotidiana de los ciudadanos, máxime la del impaciente Calisto.

En cuanto a los aspectos urbanísticos de la ciudad, se nombran las afueras o los arrabales (Elicia, XV.199), con las tenerías cerca del río, y dentro de la muralla se habla de los barrios (Lucrecia, IV.88) y de sus moradores o vezinos (Alisa, IV.90), a la vez que se alude a las distancias que hay que recorrer, se nombra varias veces a la plaza (Sempronio, VIII.140) y, sobre todo, se habla de las calles, siendo esta palabra una de las más frecuentes en este campo léxico, alcanzando 32 menciones (proferidas, en su mayoría, por la andariega Celestina ${ }^{7}$ ). A éstas hay que añadir 20 menciones más de su sinónimo, camino, ${ }^{8}$ que a su vez enriquece la indicación de los muchos itinerarios urbanos que los personajes tienen que recorrer. Pera el léxico de la caminería en LC también dispone de palabras como encrucijada (Celestina, VII.124), puente (Celestina, III.80), rincón (Elicia, XV.198), y luego de varios verbos de movimiento (como ir, venir, andar, caminar, pasar, pasear, aguijar, haldear éste referido a Celestina-, y además huir, escapar, rondar, rodear, alcanzar, entrar, salir, subir, bajar, encontrar, topar, llevar, y muchos más). Cuenta a

\footnotetext{
${ }^{6}$ Por ejemplo la escena primera del auto XI.163 y ss. Ver también nuestra n12.

${ }^{7}$ Celestina: III.82, IV.87, VII.123, VII.132, XI.163, XI.167, XII.180.

${ }^{8}$ Celestina: III.82, III.83, IV.86, VII.125, X.160.
} 
la vez con términos relacionados con el acto mismo del caminar, como pies (Celestina, IV.98), zapatos (Celestina, XI.167), pasos (normalmente referidos a la alcahueta: Celestina, III.81 y 85; IV.86; VII.126), y en fin, con palabras que indican los componentes materiales de la calle: poyo, calzada, muro, cantos (Celestina, XI.167), suelo (Sempronio, V.103; Pármeno, V.105), tierra (Calisto, I.64). También hay los numerosos obstáculos que en la calle se encuentran, como piedras (Celestina, IV.87; Melibea, XX.230), hoyos (Melibea, XIV.189), y que la vuelven peligrosa para una mujer de edad.

En la calle, como se ha dicho, se desenvuelven muchas de las escenas incorporadas a la acción, y ello ocurre tanto de día como de noche, cuando las calles son más temerosas, porque son oscuras y desiertas (Calisto, XII.169) y se corre el riesgo de asaltos (Celestina, XI.167; Pleberio, XXI.233) o de violaciones que vuelven necesario escoltar con pajes y hachas a Celestina (Pármeno, VI.112), o incluso son peligrosas porque pasa el alguacil, la ronda (Sempronio, XII.176), o porque se oyen ruidos improvisos y siniestros (Melibea, XII.176; XX.230; Calisto, XIX.223), que, no se olvide, a Calisto le serán fatales.

Por lo demás, hay que decir que en el texto de LC todas las indicaciones de la ciudad surgen de los parlamentos entre los personajes, mientras las referencias a la calle se dan tanto en el diálogo, a manera de acotación, como en los Argumentos, a manera de leyenda o de titulillo (Argumentos: V.102, XI.162 y XII.168).

Por lo que concierne a las varias fases de la redacción del texto, podemos observar que un pequeño grupo originario de términos de caminería se halla ya en la primitiva redacción de la obra (o Esbozo del I Auto), ${ }^{9}$ siendo después sumamente enriquecido en la Comedia ${ }^{10}$ y escasamente aumentado, o apenas mantenido, cuando no eliminado, en las interpolaciones de la Tragicomedia posterior. " Es decir que el núcleo principal de las palabras camineras y ciudadanas pertenece a la parte que

${ }^{9}$ Entre ellos, ciudad, calle, camino, plaza, tierra, vezindad, pie, piedra, pared, iglesia, monasterio, templo, y además los oficios enumerados por Pármeno.

${ }^{10}$ En la Comedia, amén de aumentar las menciones de cada una de las palabras ciudadanas y camineras ya aparecidas en el Esbozo, se introducen varios términos nuevos, a saber: torre, muro, suelo, barrio, feria, mercado, tienda, passos, haldear, aguijar, cementerio, hospital, taberna, mesón, alguacil, médico, cirujano, etc.

11 En la nueva redacción en 21 actos se introducen muy pocos términos nuevos, entre ellos: edificio, cantos, hoyos, calzada, poyo, zapatos, bodegones, alcalde. 
se puede atribuir a Rojas, y ello además concuerda con el desarrollo de la acción dramática, ya que los personajes portadores de la gran mayoría de términos, que a su vez son los personajes más andariegos, o sea Celestina, Sempronio y Pármeno, mueren, como es sabido, en el auto XII. Curiosamente, el autor de las Adiciones ha usado muy poco ese campo léxico, mientras, por el contrario, en el Auto de Traso, añadido al texto a partir de 1526, vuelven a ser muchísimas, aun en pocas páginas, las referencias a las calles y a la ciudad. ${ }^{12}$

Interesante es notar, además, que en el texto no faltan los refranes de la calle, como por ejemplo estos dos que profiere Celestina en el auto XI: "no da passo seguro quien corre por el muro," y "aquel va más sano que anda por llano" (Celestina, XI.167). Y éstos amén de muchos otros proverbios alusivos al caminar o incluso a la ciudad, a sus casas y a sus puertas, que encontramos a lo largo de $\mathrm{LC}^{13}$ y que también volvemos a leer en el Auto de Traso añadido en $1526 .{ }^{14}$ El recurso al refrán callejero o caminero demuestra, a nuestro parecer, que calles, caminos, plazas, y la misma ciudad son tan vivos y tan omnipresentes en LC que incluso aparecen cristalizados en fórmulas, o lexicalizados en frases hechas con las que el autor nuevamente los propone a la atención del lector, bajo un traje lingüístico pre-fijado y encima haciéndole un guino al acudir al patrimonio mnemónico común.

${ }^{12}$ Ver en la edición llevada a cabo por Manuel Criado de Val (Madrid: CSIC, 1958) la pág. 314, renglón 11 , y además las pp. 314.16, 314.24-25, 314.27-28, 315.8, 315.28 , 315.34-37, 316.11, 316.23, 316.36, 317.4, 317.8-9, 318.3-17, 318.28-30, 318.32, $319.3,319.12$.

${ }^{13}$ Por ejemplo "las paredes han oídos" (Sempronio, I.59), "los peregrinos tienen muchas posadas y pocas amistades" (Celestina, I.68), "a tuerto o a derecho, nuestra casa hasta el techo" (Celestina, I.69), "la distancia de las moradas no despega el amor de los corazones" (Celestina, IV.89), "hablas de la feria según te va en ella" (Melibea, IV.91), "pan y vino anda camino, que no moço garrido" (Celestina, IV.94), "la vieja como yo que alce sus haldas al passar del vado" (Celestina, V.103), "nunca da menos de doze, siempre está hecho relox de mediodía" (Pármeno, VI.110), "nunca harás casa con sobrado" (Celestina, VII.), hecho tablilla de mesón, que para sí no tiene abrigo y dale a todos" (Sempronio, VIII.136), "el sotil ladrón siempre rodea las ricas moradas" (Alisa, X.162), "te hizo alcalde mengua de hombres buenos" (Calisto, XIV.194), "quiero ir abrir, que es loco o privado" (Areúsa, XVII.209), y "a essotra puerta" (Sosia, XIX.224).

${ }^{14}$ Ver por ejemplo en la ed. Criado cit.: "por mejor tengo ir solo que mal acompañado" (Centurio, 314.20), "huesped con sol..." (Centurio, 315.26), "muerto es por quien tañían" (Traso, 317.15). 
Todo el ambiente urbano celestinesco que acabamos de señalar también es muy evidente en las viñetas de las ediciones antiguas del texto, que van ilustrando, o mejor 'historiando', el contenido de la obra que acompañan. Así, por ejemplo, como puede verse en las reproducciones adjuntas (hoja $A$ ), al lado de las figuras que indican a las dramatis personae al comienzo de cada auto, nunca falta en posición lateral o central la representación de una ciudad, que a veces incluso es doble, como puede apreciarse en las láminas 1 y 4.

Además, en algunas ediciones primitivas, los grabadores han dado gran relieve al tema de la calle, captando perfectamente la evidencia y el sentido que ésta tiene en la obra de Rojas: así por ejemplo, como puede verse en la hoja B, en la edición de Burgos de 1499 hay gran profusión de escenas callejeras, con varios personajes que caminan, tocan a las puertas, salen, entran, dialogan o bien van solos profiriendo soliloquios. En la misma hoja (lámina 9), otra edición antigua, la de Valencia 1514, representa en su portada una plaza donde se supone está la casa de Melibea, con su huerta toda llena de flores.

La huerta de Melibea sigue siendo el tema de las ilustraciones siguientes (hojas $\mathrm{C}$ y D), en las que se reproducen las portadas de cuatro ediciones antiguas, todas ellas alusivas al encuentro entre los dos amantes yendo Calisto en busca de su halcón (que en tres de ellas está representado; a veces con un caballo que confirma el motivo de la caza). Curiosamente, en casi todas las ediciones antiguas la huerta de la portada difiere de la que figura en los autos XIV y XIX (hoja D): si bien algunos elementos son comunes (vuelven a aparecer flores y árboles, y sobre todo cipreses), cambian sin embargo los elementos arquitectónicos de la casa de Melibea, aun dentro de una misma edición (véase para Burgos 1499, hoja C, lám. 1 y hoja D, lám. 1, y más sensiblemente para Valencia 1514, hoja $B$, lám. 9 y hoja $D$, láms. 3 y 4). La última serie de viñetas (hoja $E$ ) representa la muerte de Celestina y la ejecución de Pármeno y Sempronio ambientada en la plaza principal de la ciudad.

En su conjunto esas ilustraciones parecen adherirse al ambiente evocado en la obra de Rojas, incluso reproduciendo algunos detalles ínfimos, como las piedras que abundan por las calles y que dificultan el acto del caminar, según refiere varias veces Celestina, y ello ocurre por ejemplo en las vinetas de Burgos 1499 (hoja B, láms. 2 y 4) y de Valencia 1514 (hoja $D$, láms. 2 y 3). Por último hay que decir que en las ilustraciones faltan en general los elementos locales, e incluso en algunas de ellas (hoja A, láms. 1 y 2) las casas representadas parecen más bien nórdicas, quizás por ser más familiares a los tipógrafos primitivos, en su mayoría suizos o alemanes. 
La falta de elementos locales, en realidad, es la otra cara de la medalla de los aspectos urbanos de LC. Característica, en ese sentido, es la escasez de nombres propios de tipo geográfico ${ }^{15}$ o urbanístico en el texto: entre las calles, se nombran tan sólo dos, y encima con rótulos de lo más genéricos, o sea la calle del Arcediano (Celestina, XI.163), situada cerca de la iglesia de la Magdalena, y la calle del Vicario Gordo (Sosia, XVIII.212), a las espaldas de la casa de Melibea. Ambas, como se ve, parecen calles no rotuladas y denominadas así más bien por el nombre de sus habitantes (el segundo incluso podría identificarse con "el ministro el gordo" de que se habla en el ${ }^{\circ}$ auto [Celestina, I.57]). También las dos iglesias que nos son especificadas (la Magdalena ${ }^{16}$ y San Miguel (Sempronio, XII.176) carecen de caracterización local, siendo que en varias ciudades españolas las hay con este nombre. Los únicos nombres propios que parecen implicar reminiscencias de una determinada localidad de España son los que mencionan Sempronio y Pármeno en el auto XII, o sea "los frailes de Guadalupe," famoso monasterio de los Jerónimos en provincia de Cáceres, y "Mollejas el hortelano" (Pármeno y Sempronio, respectivamente, XII.176) que según han demostrado Valle Lersundi y Gilman constituye una reminiscencia personal de Rojas de la Puebla de Montalbán.

La ciudad de LC no se nombra, aunque esté tan pormenorizada su descripción: pese a tanto realismo, permanece anónima y sigue lanzando su desafio a todo lector que quiera identificarla a toda costa. Si bien ésta ha sido una discusión muy animada a fines de siglo pasado y

15 En realidad en LC se nombran a varias ciudades españolas y extranjeras, pero nunca para localizar a la acción del texto: por lo general, su mención sirve para recordar alguna calidad sobresaliente de la ciudad o bien forma parte de alguna frase hecha: por ejemplo, entre las españolas: "ganada es Granada" (Celestina, III.80), "en una hora no se ganó Zamora" (Celestina, VI.114), "broqueles de Barcelona" (Centurio, XVIII.216), "capacetes de Calatayud" (ibid.), "caxquetes de Almacén" (ibid.). También se citan los vinos de Monviedro, Luque, Toro, Madrigal y San Martín (Celestina, IX.152). La única ciudad que es nombrada en relación a LC misma es Salamanca ("Yo vi en Salamanca la obra presente" Octavas Acrósticas.39). Entre las ciudades extranjeras se nombra a Roma (I.49, VII.124, XIV.195, XX.228), Milán (Carta.36), Venecia (VII.134), Atenas (XIV.194, Octavas de Proaza.238), Troya (IV.97. VI.115), Jerusalén, Belén (I.56), y también se menciona a Egipto, Judea, Macedonià, Capadocia, Bitinia, etc.

${ }^{16}$ Calisto, VIII.140, Pármeno, IX.147, Argumento, XI.162, Celestina, XI.163, Calisto, XII.174. 
principios del presente, ${ }^{17}$ en las últimas décadas no han faltado los estudiosos que la han vuelto a cultivar: así por ejemplo en 1958 Azorín coordinaba un "Debate sensacional" sobre el tema "¿Dónde colocamos la acción de LC?," en las "Páginas Literarias" del periódico Arriba, ${ }^{18}$ invitando para ello a los defensores de las tesis más opuestas. $O$ incluso, más recientemente, pese a los innúmeros juicios críticos que dejaban sentado que se trata más bien de una ciudad ideal con reminiscencias de varias castellanas, ${ }^{19}$ y pese a las exhortaciones a dejar de lado ese afán de encontrar los 'modelos vivientes' a toda costa, como por ejemplo las de Kirby, no han faltado los trabajos que han vuelto a plantear la cuestión de la localización de la obra. $Y$ sobre todo, a las tradicionales candidatas como Sevilla, Toledo, Talavera, Cuenca, y otras más, ${ }^{20}$ se ha vuelto a proponer recientemente Salamanca, ${ }^{21}$ a base de testimonios muy antiguos, ${ }^{22}$ de tradiciones folkóricas locales, ${ }^{23}$ de alusiones

${ }^{17}$ Ver la reseña crítica y la bibliografía citada por M. R. Lida en la nota 6 de la p. 163 de su Originalidad.

${ }^{18}$ Ver Bibliografía, s.v. Martínez Ruiz.

19 Así opinaron varios estudiosos, entre ellos Menéndez Pelayo, Lida de Malkiel, Maravall, Gilman, Rodríguez Puértolas, etc.

${ }^{20}$ Para las distintas posturas de los críticos al respecto, ver n6 de M. R. Lida (citado) y además el "Debate sensacional" (citado). Los principales argumentos fueron, para Sevilla, los navíos que se ven desde la torre de la casa de Melibea (Melibea, XX.227), para Toledo, la existencia de las tenerías, de la calle del Arcediano, de la iglesia de la Magdalena y de la de San Miguel (pero todas ellas han sido localizadas también en otras ciudades españolas, entre ellas Salamanca); y para Talavera de la Reina, la visita del embajador francés (Ruiz y Villasante), de que se habla en el auto I (Pármeno, I.62).

${ }^{21}$ Posteriormente al "Debate" citado, la defendieron, entre otros, hacia el final de los años '50, Maldonado de Guevara y Romero Sarráchaga, luego en la década de los '70, Rubio García y Castellanos, y en años más recientes, Severin/Snow, Russell, Michael y Márquez Villanueva.

22 Entre los testimonios antiguos que aluden a la casa de Celestina en Salamanca aducidos por los estudiosos, ante todo está la larga serie de obras que forman parte del género de la celestinesca, ambientadas explícitamente en Salamanca (como por ejemplo la Tragicomedia de Lisandro y Roselia de Sancho de Munón, de 1542, o la recién descubierta Tragicomedia de Polidoro y Casandrina, posterior a 1564, cfr. la noticia publicada por S. Arata en Celestinesca 12.1 [mayo 1988]: 45-50). Lo mismo refieren la Lozana Andaluza (1528), Amato Lusitano en sus comentarios a Dioscórides (1553), Bartolomé de Villalba y Estaña en su Pelegrino 
implícitas en el texto ${ }^{24}$ y a base también de la historia de las Universidades y sobre todo de la prostitución. ${ }^{25}$

Por nuestra parte, consideramos mucho más fecunda y sugestiva la indefinición que no la hipótesis concreta sobre tal o cual ciudad. A fin de cuentas, si el autor ha querido no nombrarla, poco importa. Sí importa, en cambio, la idea de ciudad que ha dejado bien sentada a lo largo de su obra, y que es imprescindible para enmarcar su Tragicomedia 'urbana' y para sustentar el conjunto de idas y venidas de sus personajes que serían inconcebibles fuera de itinerarios estrictamente ciudadanos. ${ }^{26}$

curioso (1577), Bernardo Gómez de Bobadilla en sus Ninfas y pastores de Henares (1587), Cesar Oudin en sus Diálogos muy apazibles (1610) y Miguel de Cervantes en La tía fingida (cuya verdadera historia sucedió en Salamanca el año de 1575).

${ }^{23}$ Como por ejemplo la creencia de la casa de Pleberio en Salamanca (Severin/Snow), o el topónimo de la Peña Celestina en la misma ciudad (Sánchez González).

${ }^{24}$ Entre ellas, la insistencia en la mudanza de casa de Celestina que se puede relacionar con edictos relativos a los judíos salmantinos y con nuevas disposiciones sobre la prostitución local (Michael), las repetidas referencias a su vieja casa cerca de las tenerías (nuestra n30) que autorizan la hipótesis de la preexistencia de la misma en Salamanca (Russell), el bonete (V.104, IX.151) como señal de presencia de estudiantes en la ciudad, que además son nombrados una vez en el texto (Pármeno, I.60; cfr. Márquez Villanueva), las repetidas alusiones al mal estado de las calles (supra: piedras, hoyos) que pueden relacionarse con la ordenanza de pavimentación de las calles salmantinas emanada en 1497 (Michael), etc.

${ }^{25}$ Máxime de la conexión entre Universidad y prostitución en la ciudad de Salamanca.

${ }^{26}$ Un "gracias" muy especial a Daniela Tarizzo que ha colaborado al preparar las láminas adjuntas y que además me ha ayudado a seleccionar en LC varios pasajes dignos de atención. 

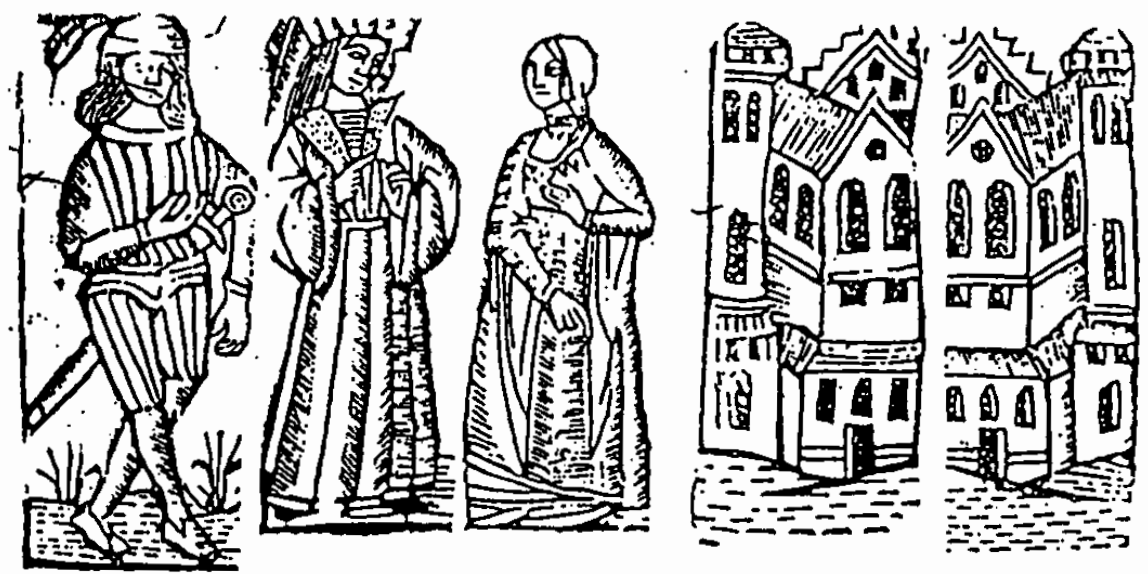

Lám. 1 - Toledo 1510-1514, auto I

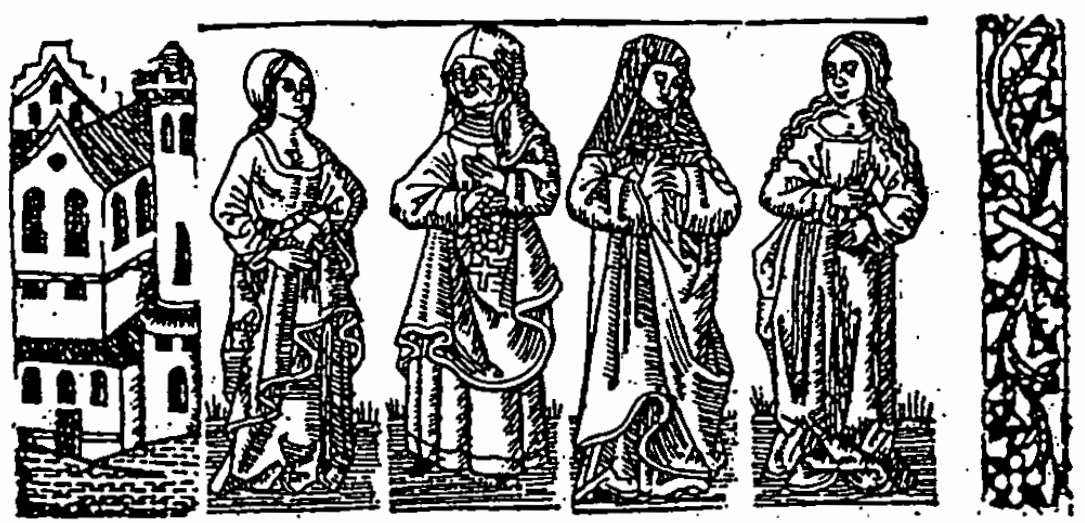

Lám. 2 - Sevilla 1511, auto IV

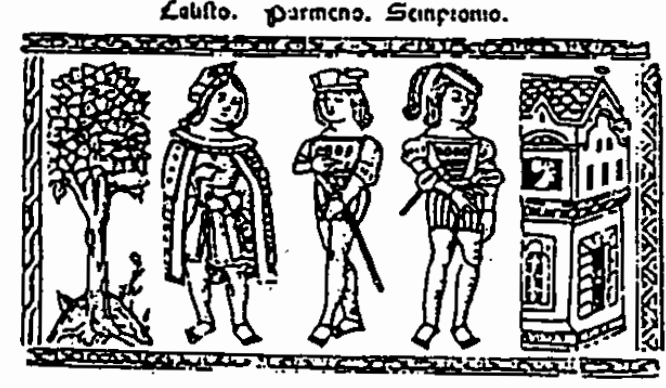

Lám. 3 - Valencia 1514, auto II

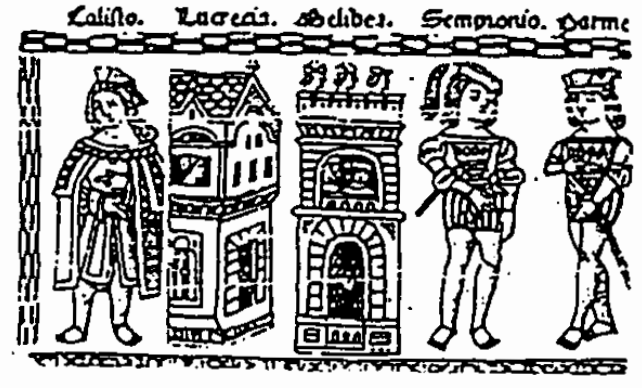

Lám. 4 - Valencia 1514, auto XI 


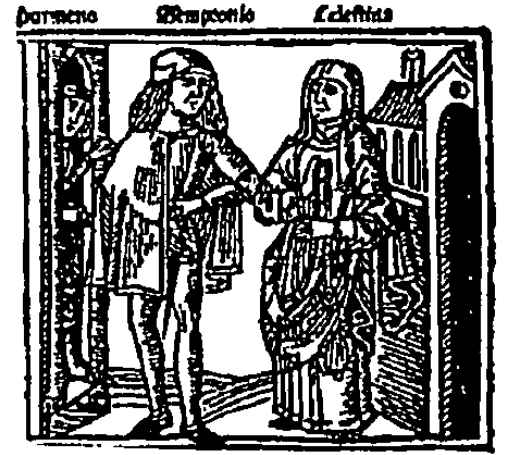

Lám. 1 - Burgos 1499, auto I

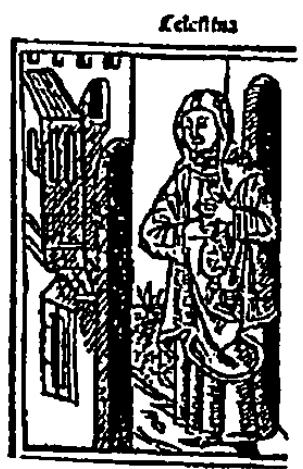

Lám. 4 - Burgos

1499, auto II

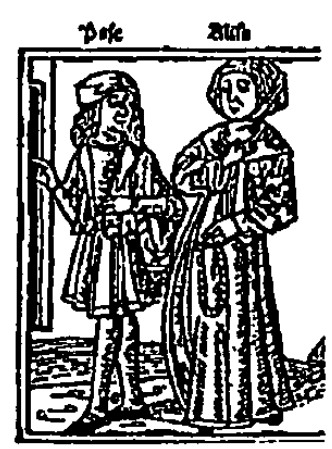

Lám. 2 - Burgos 1499,

auto IV

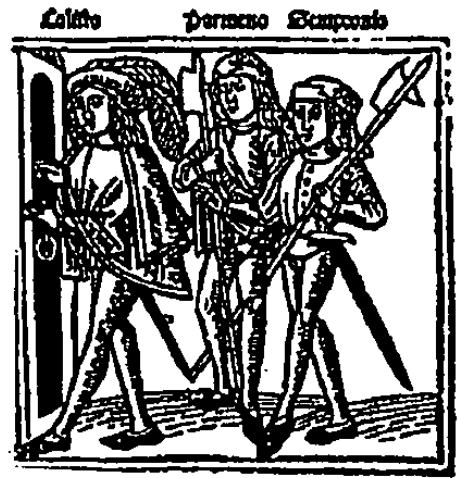

Lám. 3 - Burgos 1499, auto XII

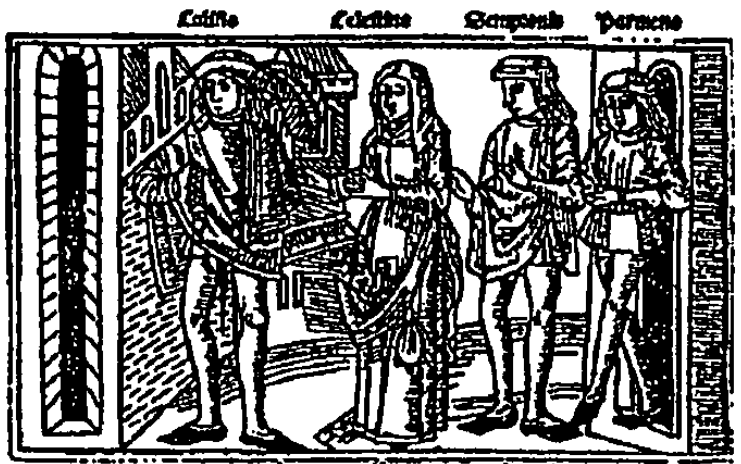

Lám. 6 - Burgos 1499, auto XI

Lám. 5 - Burgos 1499, auto III

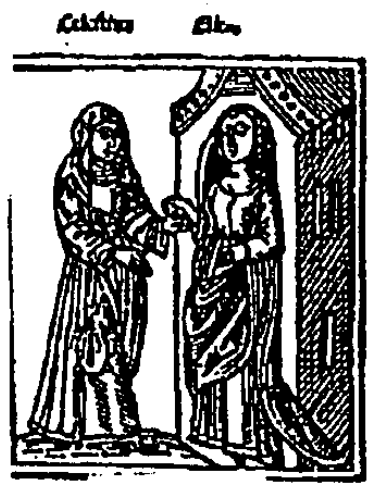

Lám. 7 -

Burgos 1499, auto VII

Lám. 8 - Burgos 1499, auto IX

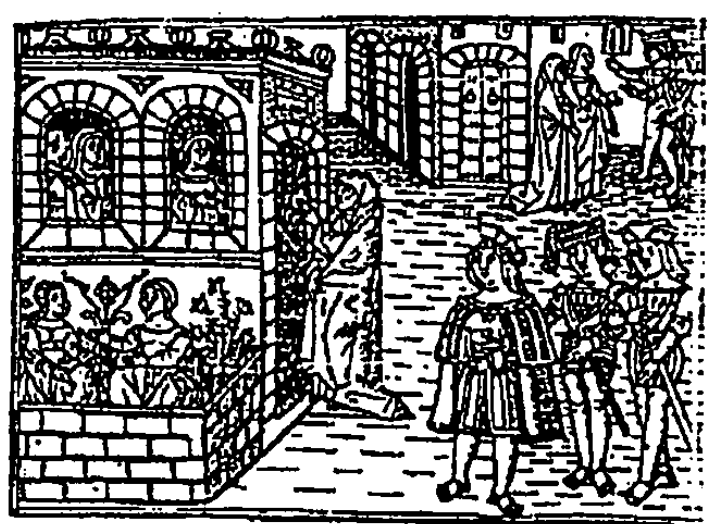

Lám. 9 - Valencia 1514, Portada 


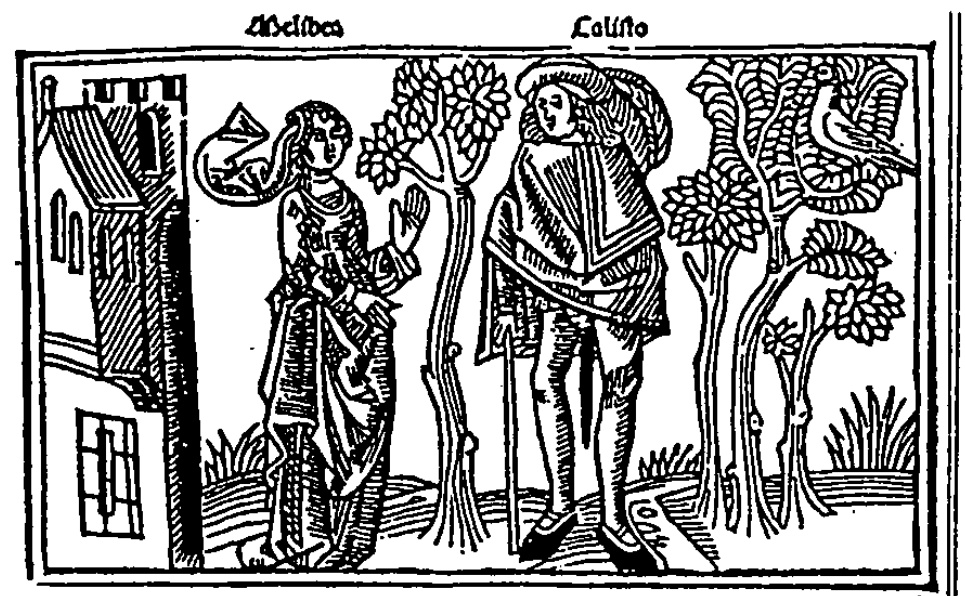

Lám. 1 - Burgos 1499, Portada

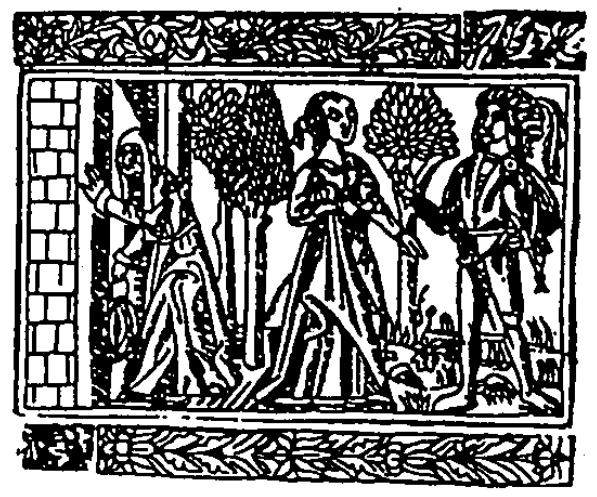

Lám. 2 - Toledo 1500, Portada

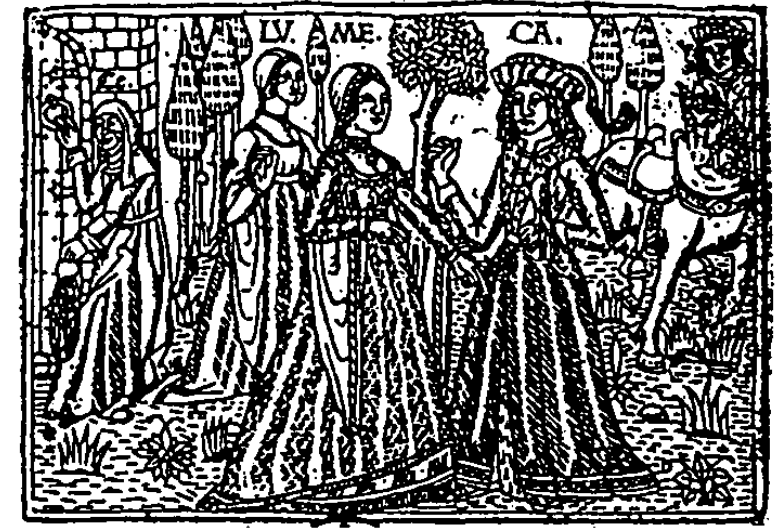

Lám. 3 - Sevilla 1501, Portada

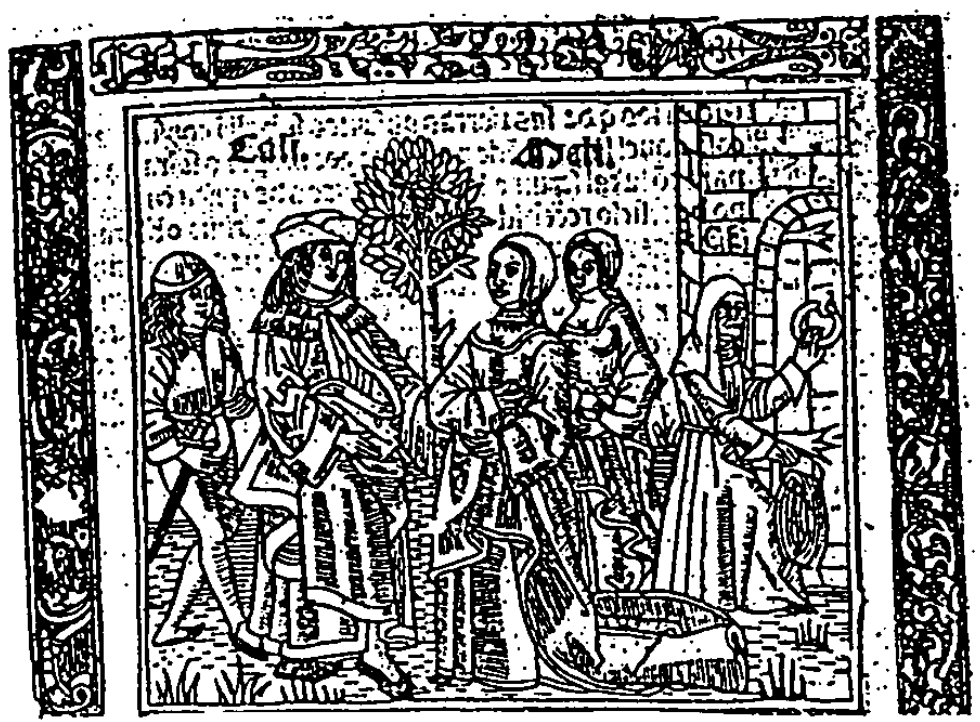

Lám. 4 - Salamanca 1543, Portada 


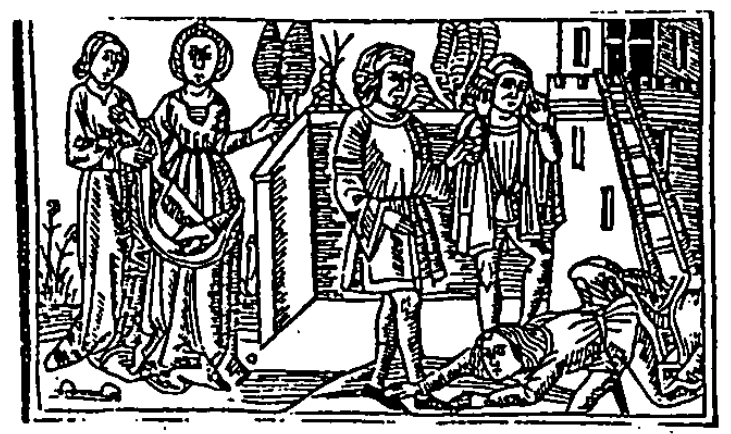

D

Lám. 1 - Burgos 1499, auto XIV

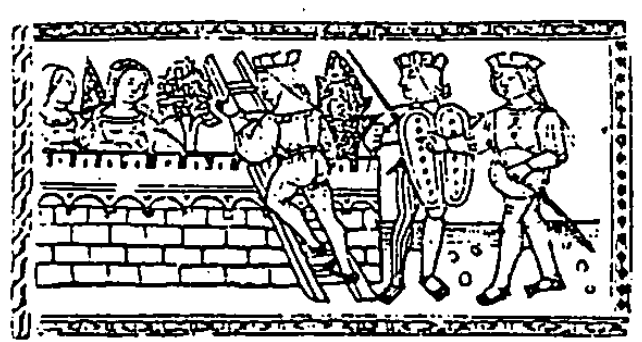

Lám. 2 - Valencia 1514, auto XDX

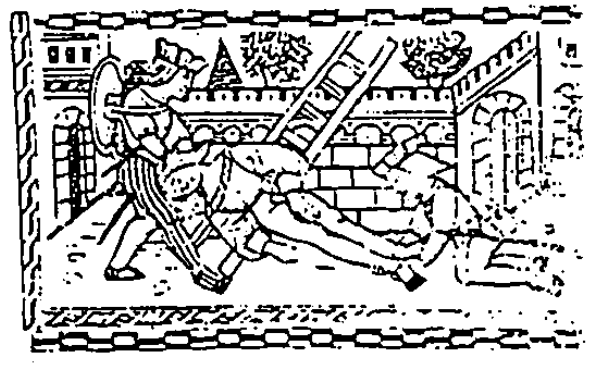

Lám. 3 - Valencia 1514, auto XIX

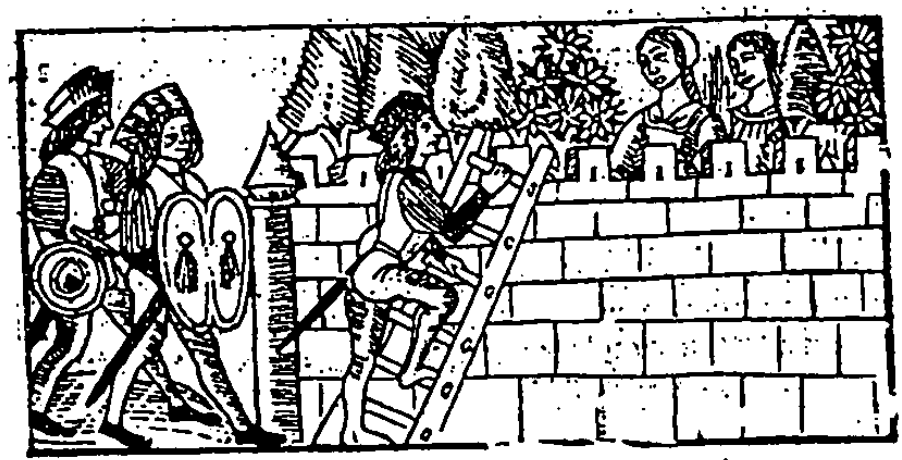

Lám. 4 - Sevilla 1511, auto XIX

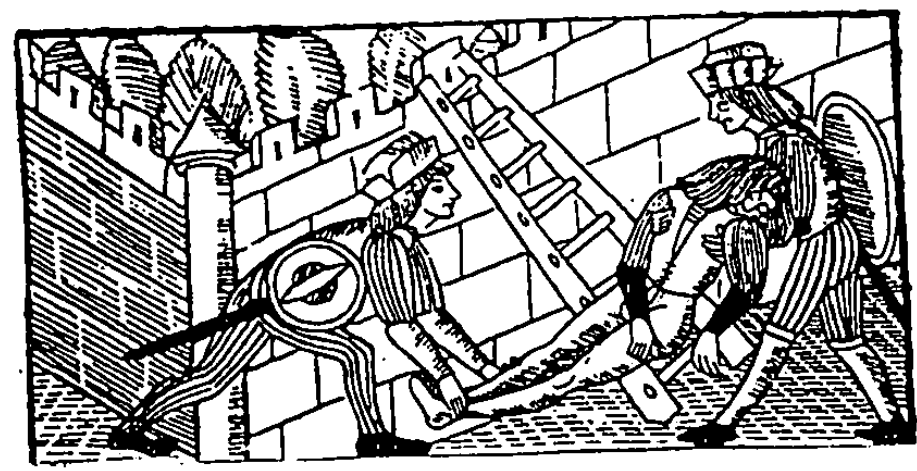

Lám. 5 - Sevilla 1511, auto-XIX 

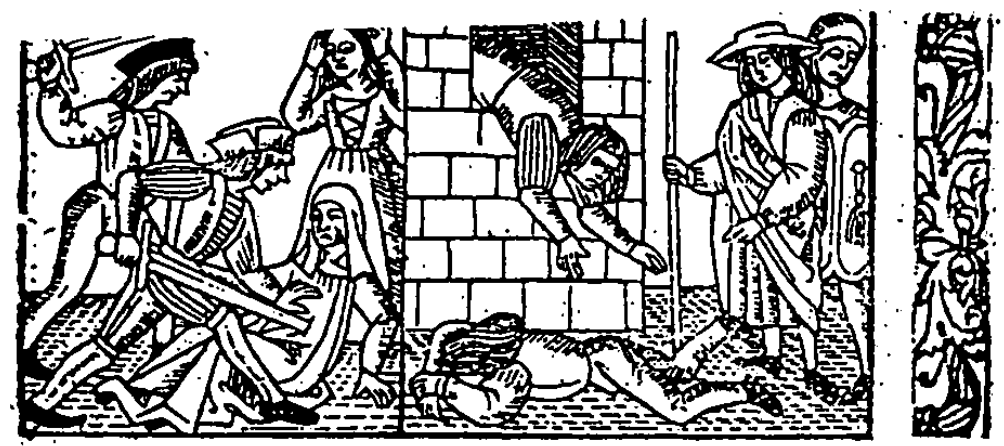

Lám. 1 - Sevilla 1511, auto XII
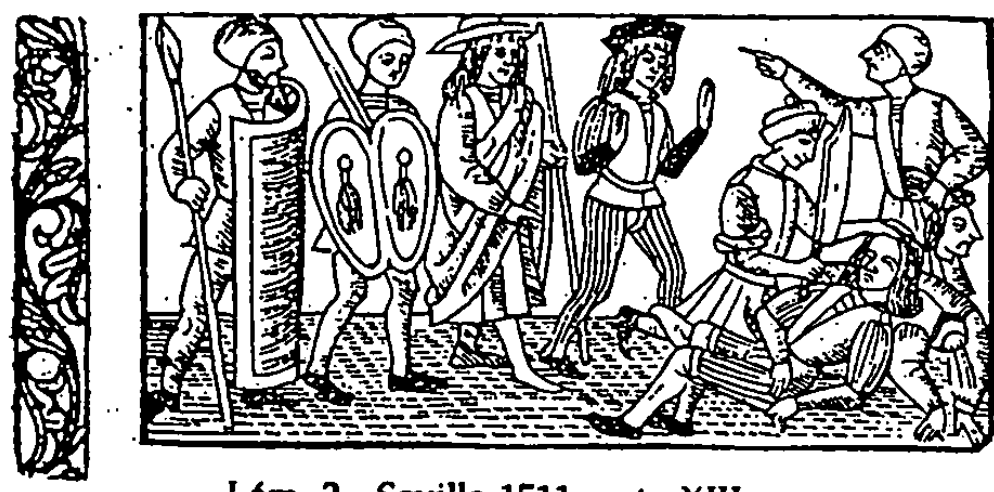

Lám. 2 - Sevilla 1511, auto XIII

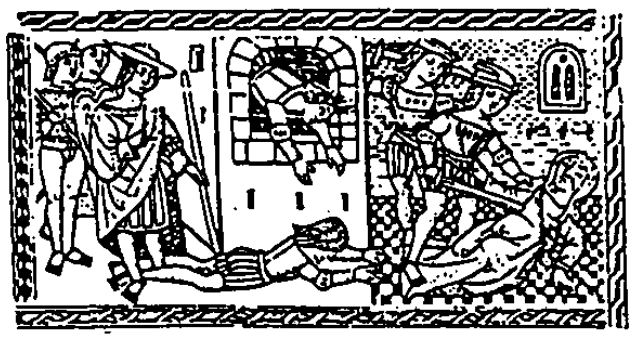

Lám. 3 - Valencia 1514, auto XII

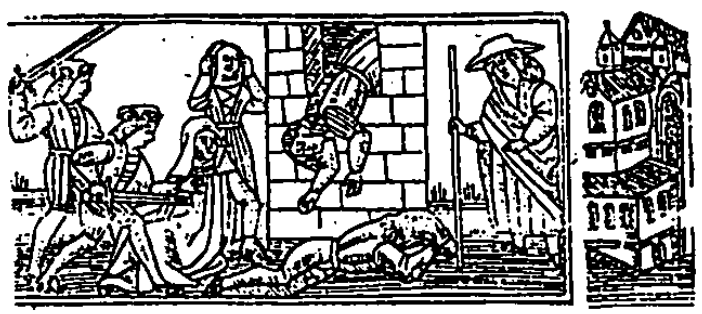

Lám. 5 - Salamanca 1543, auto XII

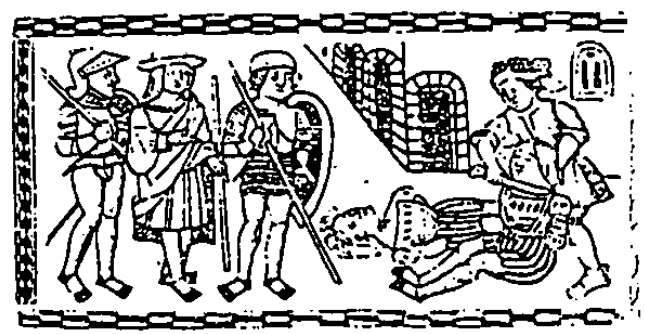

Lám. 4 - Valencia 1514, auto XIII

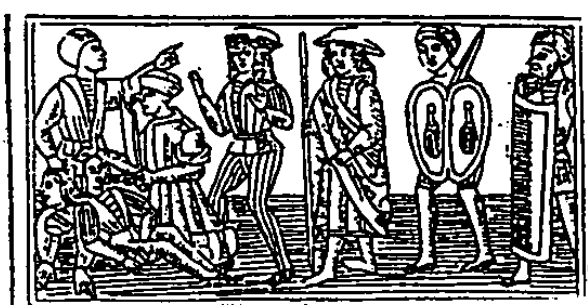

Lám. 6 - Salamanca 1543, auto XIII 


\section{BIBLIOGRAFIA SELECTA}

CASTELLANOS, Luis Arturo, "El 'ergo' andaba por las cocinas," en LC y su contorno social, Actas del I Congreso Internacional sobre LC (1974) (Madrid: Hispam, 1977). 397-400.

CZARNOCKA, Halina, "Sobre el problema del espacio en LC." Celestinesca 9.2 (1985): 65-74.

CRIADO DE VAL, Manuel, "La celestinesca," en su Teoría de Castilla la Nueva (Madrid: Gredos, 1960). 308-30.

"Siguiendo a Celestina," en su Campo literario de Castilla la Nueva (Madrid: Publicaciones Españolas, 1963). 45-47.

ELLIS, Deborah, "'Calle It Gentilesse": a Comparative Study of Two Medieval Go-Betweens," en Comitatus (UCLA) 8 (1977): 1-13. "The Image of Home in Early English and Spanish Literature," Diss. Univ. of California-Berkeley, 1981.

"¡Adiós Paredes!," Celestinesca 5.2 (Fall 1981): 1-17.

FOULCHE DELBOSC, Raymond, "Observations sur LC. II," Revue Hispanique 9 (1902): 171-199, esp. 176-79.

GILMAN, Stephen, "Fortune and Space in LC," Romanische Forschungen 66 (1955): 342-60, ampliada en The Art of LC, Madison, Univ. Wisconsin Press, 1956 (trad. esp. LC: Arte y estructura (Madrid: Taurus, 1974, cap. V, "Fortuna y espacio en LC"). 363-79).

"Mollejas el Hortelano," en Estudios Dedicados a James Homer Herriott (Madison: U Wisconsin P, 1966). 103-07.

, The Spain of Fernando de Rojas (Princeton: Princeton UP, 1972, cap.VI, "Salamanca"). 267-353.

KIRBY, Steven D., "Observaciones pragmáticas sobre tres aspectos de la crítica celestinesca," en Studia Hispanica Medievalia, II Jornadas de Literatura Espaffola (Buenos Aires: Universidad Católica Argentina, 1987). 71-79.

LIDA DE MALKIEL, María Rosa, Two Spanish Masterpieces: The "Book of Good Love" and LC. (Champaign-Urbana: Univ. Illinois Press, 1961) (trad. esp. Dos obras maestras de la Literatura Espanola: El $L B A$ y $L C$ (Buenos Aires: EUDEBA, 1966), esp. pp. 85-86.

, La originalidad artística de LC (Buenos Aires: EUDEBA, 1966, cap. "El Lugar"). 149-168; "La localización," pp. 162-68.

"El ambiente concreto en LC. Fragmentos de un capítulo no aprovechado para La originalidad artística de 'LC'," en Estudios dedicados a James Homer Herriott (Madison: U Wisconsin P, 1966). $145-64$.

LIHANI, John, "Spanish Urban Life in the Late Fifteenth Century as seen in LC," Celestinesca 11.2 (nov. 1987): 21-28.

MACAYA LAHMANN, E., "La evocación local española en LC" [1935], y "La evocación local española en el grupo de las Celestinas," 
reed. en sus Estudios Hispánicos (San José de Costa Rica: Soley y Valverde, 1938), II: 31-40 y 43-58.

MALDONADO DE GUEVARA, Francisco, "La casa de Celestina," Anales Cervantinos 7 (1958): 287-89.

MARAVALL, José Antonio, El mundo social de LC (Madrid: Gredos, 1964, cap. III "Afán de lucro y economía dineraria. El mundo celestinesco como producto de la cultura urbana"). 50-67.

MÁRQUEZ VILLANUEVA, Francisco, "La tía fingida: literatura universitaria," en On Cervantes: Essays for L. A. Murillo, ed. by James A. Parr (Newark, Delaware: Juan de la Cuesta, 1991). 11948.

Origenes y sociologia del tema celestinesco (Barcelona: Anthropos 1993): "Sociología de la lujuria universitaria," pp. 124-129; "La alcahuetería, problema de policía urbana y universitaria," pp.13037.

MARTÍNEZ RUIZ, José (=Azorín), "Tragedia en Toledo" [1934], reed. en Dicho y Hecho (Barcelona: Destino, 1957). 23-36.

¿¿Dónde colocamos la acción de la Comedia de Calisto y Melibea?: Debate sensacional," en "Páginas Literarias" de Arriba (9-III-1958). 21-22; (16-III-1958). 25-26; (23-III-1958), 32; (10-VIII-1958). 31-32.

MENENDEZ PELAYO, Marcelino, "LC" [1895], ampliado en sus Orígenes de la novela [1905-1915] (reed. en la Edición Nacional de las Obras Completas de Menéndez Pelayo, $2^{\mathrm{a}}$ ed. (Madrid: CSIC, 1943, 4 vols.; vol. 3, "LC," pp. 219-458; "Lugar en que pasa la escena". 276-81), y en Col. Austral núm. 691 (Madrid: Espasa, 1947).

MICHAEL, Ian, "Por qué Celestina muda de casa," en Literatura Medieval, Actas do IV Congresso da Associação Hispânica de Literatura Medieval (Lisboa 1-5 octubre 1991) (Lisboa: Ed. Cosmos, 1993). Vol. 3: 69-89.

MORALES, Rafael, "Otro escenario más para LC," en Cuadernos de Literatura (Madrid) 7 (1950): 221-31.

NIVEIRO, Emilio, "LC y Talavera," en $A B C$ (25-VI-1974).

RAMOS JIMÉNEZ, José, "'Algo más que tenerías': Algunas notas en torno a la localización de LC," Salamanca: Trabajos y Días, 1950 (8 pp.).

RODRÍGUEZ PUERTOLAS, Julio, "Nueva aproximación a LC" (1969), reed. en su De la Edad Media a la edad conflictiva (Madrid: Gredos, 1972). 217-42.

ROMERO Y SARRACHAGA, Federico, Salamanca, teatro de LC, con algunos apuntamientos sobre la identidad de los autores (Madrid: Escelicer, 1959).

RUBIO GARCIA, Luis, "Más sobre LC," en Anales de la Universidad de Murcia 28 (1969-70): 4-139. 
RUIZ, Higinio, y Carmen BRAVO-VILLASANTE, "Talavera de la Reina (1479-98), ¿lugar de acción de LC?," en Anuario de Estudios Medievales 3 (1966): 553-62 (también en Actas del Il Congreso Internacional de Hispanistas (1965) (Nijmegen, 1967). 525-41).

RUSSELL, Peter E., "Why Did Celestina Move House?," en The Age of Catholic Monarchs 1474-1516 (Bulletin of Hispanic Studies Special Issue in Memoriam K. Whinnom, Liverpool Univ. Press, 1989). 155-61.

SÁNCHEZ GONZÁLEZ, A., "La peña Celestina" [1928], reed. en Celestinesca 7.2 (nov. 1983): 23-24.

SAMONA, Carmelo, "LC," en La Letteratura Spagnola dal Cid ai Re Cattolici (Firenze: Sansoni-Accademia, 1972). 215-49; "La struttura itinerante," pp. 232-36; "LC tragicommedia urbana," pp. 236-43.

SEVERIN, Dorothy S. y Joseph T. SNOW, "La casa de Pleberio en Salamanca," Celestinesca 12.1 (mayo 1988): 55-58.

VALLE LERSUNDI, F. del, "Anotaciones a LC," El Diario Vasco 8 (5-VIII$58)$, p. 8.

VOLKENING, Ernesto, "LC enfocada desde otro ángulo," Eco 92 (dic. 1967): $140-60$.

ZERTUCHE, F. M., "La Comedia o Tragicomedia de Calisto y Melibea," Artes y Letras 3, núm. 6 (30-VI-1946), pp. 1 y 5.

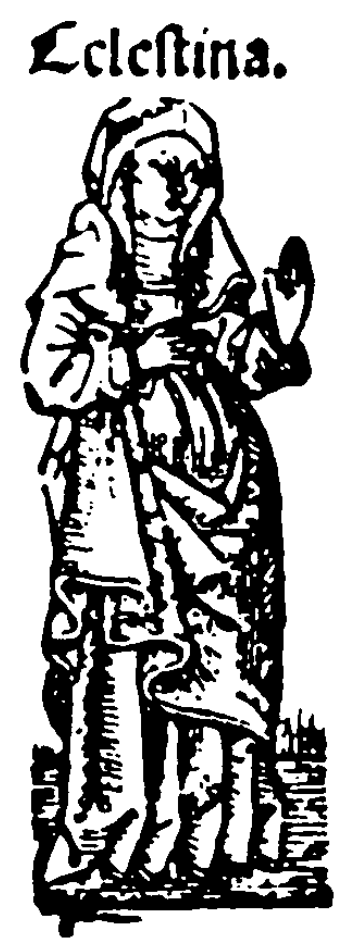

J. Cromberger, Sevilla 1535 


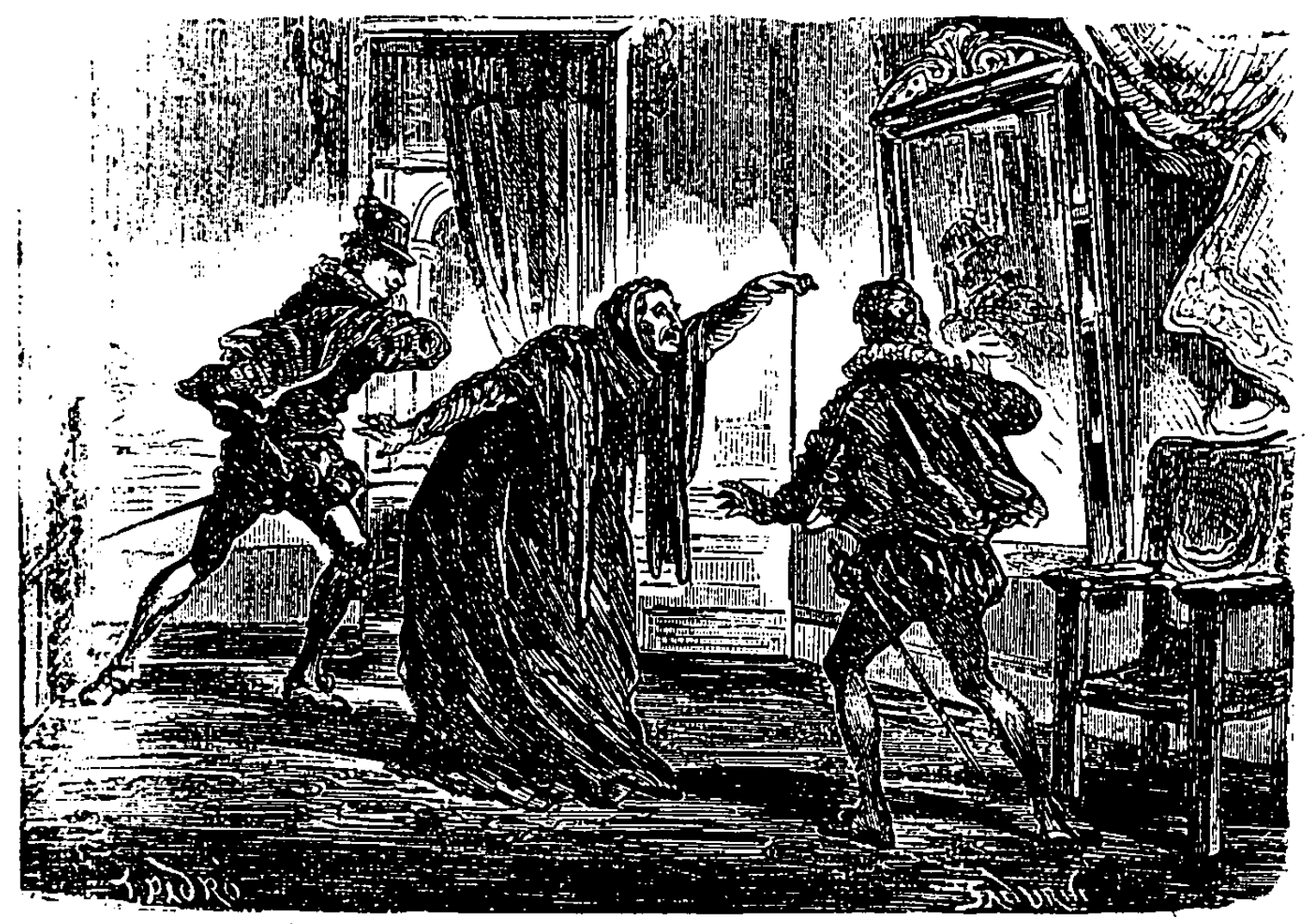

JORNADA SEGUNDA, BSCBNA XEI.

\section{SALAZAR Y TORRES}

\section{EL ENCANT0 ES LA HERMOSURA. LA SEGUNDA CELESTINA (a).}

Grabado reproducido en la edición de la obra por

T. A. 0'Connor (Binghanton, HY: HRTS, 1994) 